\title{
Enhancement Effect of Gibberellic Acid and Kinetin on Sucrose Metabolism in Mungbean Seedlings Under Arsenate Toxicity
}

\author{
Arpita Swarnakar \\ Department of Botany, Bangabasi College, University of Calcutta, West Bengal, India \\ Email address: \\ aswarnakar2@rediffmail.com \\ To cite this article: \\ Arpita Swarnakar. Enhancement Effect of Gibberellic Acid and Kinetin on Sucrose Metabolism in Mungbean Seedlings Under Arsenate \\ Toxicity. American Journal of Bioscience and Bioengineering. Vol. 5, No. 1, 2017, pp. 50-55. doi: 10.11648/j.bio.20170501.18
}

Received: January 28, 2017; Accepted: February 13, 2017; Published: February 25, 2017

\begin{abstract}
Arsenic pollution is at present an emerging global crisis. Arsenic is a naturally occurring metalloid found in water, soil and air from natural and anthropogenic sources. Currently, Arsenic pollution has gained a burning global importance due to its toxic effects. Growth of major pulse crop Mungbean (Vigna radiata (L.)Wilczek) was affected right from seedling stage when treated with Sodium arsenate $\left(\mathrm{Na}_{2} \mathrm{HAsO}_{4} \cdot 7 \mathrm{H}_{2} \mathrm{O}\right)$. With the increase in concentration of Sodium arsenate $(5 \mu \mathrm{M}, 10 \mu \mathrm{M}$ and $20 \mu \mathrm{M})$ significant decrease in seedling length, water content and primary leaf area was observed. The vital pigments like chlorophyll, caroteniod content as well as Hill activity reduced appreciably in sodium arsenate treated seedlings which indicates poor photosynthetic metabolism. Arsenate exposure also altered metabolism of main photosynthate, sucrose. Arsenate toxicity led to decrease in reducing and non reducing sugar content in the mungbean seedlings whereas starch content was elevated. Pretreatment of mungbean seeds with Phytohormone$\mathrm{GA}_{3}$ and Kinetin could ameliorate Arsenate induced toxicity to different extent in terms of growth and sucrose metabolism. Thus, the use of $\mathrm{GA}_{3}$ and Kinetin may help to resist the arsenic toxicity in seedling stage, to some extent, in arsenic contaminated areas.
\end{abstract}

Keywords: Vigna radiata, Sodium arsenate, Phytohormones, Gibberellic acid, Kinetin, Sucrose Metabolism

\section{Introduction}

Arsenic pollution is at present an emerging global crisis. Groundwater contamination by Arsenic (As) has been reported from many countries. In many countries, arsenic contaminated ground water is extensively used for irrigating crops. The impact of this contaminated water for irrigating pulse fields is of much concern as mungbean is a major pulse crop of world population. Productivity of crop plants is bound to suffer when irrigated with water contaminated with Arsenic. Plants grown in presence of arsenate or arsenite show reduced seed germination and growth $[1,2]$. Elevated soil As level resulting from long term use of arsenic contaminated groundwater for irrigation inhibit rice seed germination and seedling establishment. There are a number of studies investigating the effect of As on different plant species including rice [3] but little work has been done on mungbean crops. Pulse crop, Mungbean is also an important crop and principal source of protein in Indian diet. The mature seeds of mungbean contain as high as $24 \%$ protein. Yield of Mungbean is bound to suffer if As toxicity becomes prevalent in the productive cropland where it is grown.

In recent years, much attention is being given to the use of chemical compounds which can act as possible inducers of resistance to unfavourable conditions such as abiotic stress. It is thought that the depressive effect of abiotic stress on germination could be related to a decline in endogenous levels of hormones. Phytohormones have profound role in counteracting the effects of toxic metals and metalloids. Phytohormones were found capable of reducing lead toxicity in rice seedlings [4]. Phytohormones (used as pretreatment chemicals) were also found capable of alleviating the salinity stress in mungbean plants [5]. Presoaking the seeds with optimal concentration of phytohormones has been shown to be beneficial to growth and yield of some crop species growth by increasing nutrient reserves through increased 
physiological activities and root proliferation [6].

Cytokinins or kinetin (6-furfuryl-aminopurine) play a key role in the life of higher plants. Kinetin application (presoaking seeds before planting) improved seed viability and seedling vigour as shown by lengths of the hypocotyl, radicle and the entire seedling, as well as seedling fresh weight of Egyptian cotton cultivar Giza 75 (Gossypium barbadense) [7] and Cajanus cajan [8].The exogenous application of kinetin has been found to be responsible for the cell elongation and cell division of the seedlings of Hibiscus sabdariffa, which led to the increase of fresh weight and dry matter accumulation [9]. Similar observations were reported in various other plants such as Cajanus cajan [8], Zea mays $[10,11]$ and Pisum sativum [12]. Kinetin receptor genes have been found to be regulated by changes in the osmotic conditions, indicating that their function in the osmotic stress response might be common although mechanistically not well understood [13].

Therefore, the present investigation was undertaken to examine the effect of different concentrations of sodium arsenate on the growth and development of mungbean seedlings and to find out how Arsenic disrupts sucrose metabolism by altering photosynthetic machinery and to devise ways for the restoration of metabolic alterations resulting from arsenic stress. Phytohormones, especially, $\mathrm{GA}_{3}$ and Kinetin were tried as pretreatment chemicals to combat the serious problem of arsenic toxicity and to provide a possible method of arsenic tolerance.

\section{Material and Methods}

\subsection{Plant Material and Arsenic Treatments}

Mungbean (Vigna radiata (L.) Wilczek cv. B -105) seeds, collected from Pulses and Oilseed Research Station, Berhampore, Government of West Bengal, India were treated with $0.1 \% \mathrm{w} / \mathrm{v} \mathrm{HgCl}_{2}$ solution for $2 \mathrm{~min}$ for surface sterilization and washed repeatedly with distilled water. Around 30 seeds were allowed to germinate on petridishes lined with filter paper and sodium arsenate, $\mathrm{Na}_{2} \mathrm{HAsO}_{4} \cdot 7 \mathrm{H}_{2} \mathrm{O}$, (from Merck) used as test solution at concentrations $-5 \mu \mathrm{M}, 10 \mu \mathrm{M}$ and $20 \mu \mathrm{M}$ for 5 days. The seeds soaked in distilled water for 5 days, served as control. The seeds were kept in dark and humid conditions for $24 \mathrm{hr}$ in a germinator at near about $28^{\circ} \mathrm{C}$ followed by exposure to $16 \mathrm{~h}$ photoperiod $\left(260 \mu \mathrm{mol} \mathrm{m} \mathrm{m}^{-2} \mathrm{~s}^{-1} \mathrm{PFD}\right)$. The $\mathrm{pH}$ of the solution was 6.5 throughout. The above mentioned arsenate concentrations are comparable to soil conditions and are environmentally relevant.

\subsection{Pretreatment with Phytohormones}

For the amelioration of arsenate toxicity, seeds were pretreated with Phytohormones $\mathrm{GA}_{3}(50 \mu \mathrm{M})$ and Kinetin $(10 \mu \mathrm{M})$ concentration for $24 \mathrm{~h}$ and then transferred to sodium arsenate solution (sub lethal dose, $10 \mu \mathrm{M}$ ) for next 4 days, total germination time being maintained for 5 days in all the cases. Another set of seeds were pretreated with distilled water for $24 \mathrm{~h}$ (instead of Phytohormones) and then transferred to sodium arsenate solution $(10 \mu \mathrm{M})$ for next 4 days, total 5 days. This was done to observe the growth promoting effect of the growth regulators in comparison to water.

\subsection{Morphological Studies}

After 5 days, seedling length was observed and root length and shoot length of growing mungbean seedlings were measured in all the sets. Seedling length of 10 seedlings were determined after excising the cotyledons and averaged. Estimation of leaf area of a seedling was carried out by removing the first pair of leaves (primary leaves) followed by sketching the boundary of each leaf on a graph paper. By counting the number of squares with in the boundary, the leaf area was expressed in terms of sq. $\mathrm{mm}$. Data were collected from 10 plants at a time which were selected randomly from the same set and then averaged. Fresh weight and dry weight of 10 seedlings were determined after excising the cotyledons and averaged. For estimating dry weight, the seedlings were allowed to dry in an oven at $70^{\circ} \mathrm{C}$ for 3 days. Data were collected from 10 plants at a time that were selected randomly from the same set and then averaged. Differences between dry weight and fresh weight were calculated in order to find out the water content of the seedlings. All the experiments were repeated thrice and analyzed statistically.

\subsection{Quantitative Estimation of Pigment Content}

In order to understand the pigment status of the seedlings which is of utmost importance for photosynthetic process, primary leaves of the seedlings of all the sets were collected after 5 days of growth and quantitative estimations of total chlorophyll content and carotenoid content was done. Estimation of chlorophyll, carotenoid content (carotene and xanthophyll pigments) were carried out by extracting the fresh green leaves twice with $80 \%$ alkaline acetone (containing $0.1 \mathrm{M}$ sodium carbonate) and centrifuged at $6000 \times \mathrm{g}$ for 20 mins. After centrifugation, the combined supernatants were collected and a definite volume was made up with alkaline acetone for all the sets.

Chlorophyll was estimated spectrophotometrically according to the method of Arnon [14]. The optical density values of the clear supernatant containing leaf extracts in $80 \%$ alkaline acetone were recorded in the Hitachi U-2000 spectrophotometer at $645 \mathrm{~nm}$ and $663 \mathrm{~nm}$. The chlorophyll contents were expressed in terms of $\mathrm{mg}$ chlorophyll present per gram fresh tissue. The fluorescence of the chlorophyll was monitored at an excitation wavelength $640 \mathrm{~nm}$ and emission wavelength $680 \mathrm{~nm}$ with the help of Hitachi-650-40 spectrofluorometer. Carotenoids were estimated by the method of Davies [15]. Photosynthetic non-cyclic electron transport of isolated chloroplasts also known as Hill activity was measured spectrophotometrically according to Vishniac [16], using the artificial electron acceptor dye 2, 6-dichlorophenolindolphenol (DCPIP) under the light intensity of 7500 lux. 


\subsection{Quantitative Estimation of Sucrose Content}

In order to understand the sucrose content of the seedlings which is required for normal growth and development, seedlings of all the sets were collected after 5 days of growth, and quantitative estimations of reducing sugar content, nonreducing sugar content and starch content were done. The estimation of reducing sugar was made by copper reduction method of Miller [17]. This value includes hexoses and nonfermentable reducing substances. The amount of nonreducing sugar was measured by subtracting the value of reducing sugar from the value of total soluble sugar. Estimation of starch was done by the method of McCready et al., [18].

\subsection{Statistical Analysis}

The experiments were carried out in a completely randomized design (CRD) with 3 replicates; each replica comprising a single petridish containing an average of 20 seeds. All the experiments were analyzed statistically using ANOVA table (and expressed in Critical Difference).

\section{Result and Discussion}

\subsection{Effect of Arsenate and Growth Regulators on the Growth of Seedlings}

Sodium arsenate has a drastic effect on seedling growth and photosynthetic metabolism of germinating mungbean seedlings. Seedling length including both epicotyl and shoot and hypocotyl and root demonstrated an inverse relationship to the applied molar concentrations of $\mathrm{Na}_{2} \mathrm{HAsO}_{4} \cdot 7 \mathrm{H}_{2} \mathrm{O}$. Inhibition of elongation of mungbean seedlings started at $5 \mu \mathrm{M}$ (lowest dose of As used here), became much more pronounced at $10 \mu \mathrm{M}$ (intermediate dose) and was drastic at $20 \mu \mathrm{M}$ (Table 1). Present investigation shows that Arsenic is more toxic for root growth than for shoot growth (Figure 1). Similar reports were also observed in rice seedlings [3].
Reduction of primary leaf area was also noted due to the highest concentration of sodium arsenate, $20 \mu \mathrm{M}$ and there was a stepwise reduction of leaf area with increasing concentrations of sodium arsenate. Simultaneous reduction of leaf area of the treated seedlings is naturally a consequence of inhibition of cell division and cell enlargement [19].

Sodium arsenate toxicity adversely affected the water content of mungbean seedlings. With the increasing concentrations of $\mathrm{As}(\mathrm{V})$ large scale reduction of water content of the seedling was observed. It appears that marked dehydration of seedling is one of the effect associated with growth inhibition by arsenic. Water content was also found to decrease with arsenate treatment in rice seedlings [20]. Reduction in fresh and dry weight due to As toxicity has also been reported in tomato plants [21], maize plants and bean plants [22]. The loss of water could be recovered to some extent by the application of $\mathrm{GA}_{3}$ and Kinetin. Pretreatment of mungbean seeds with $\mathrm{GA}_{3}$ could bring about maximum stimulation of seedling growth followed by Kinetin (Table 1). Again, amelioration of arsenate toxicity was achieved only by pretreating the seeds with Phytohormones while posttreatment or simultaneous treatment with sodium arsenate bore no fruitful result [23].

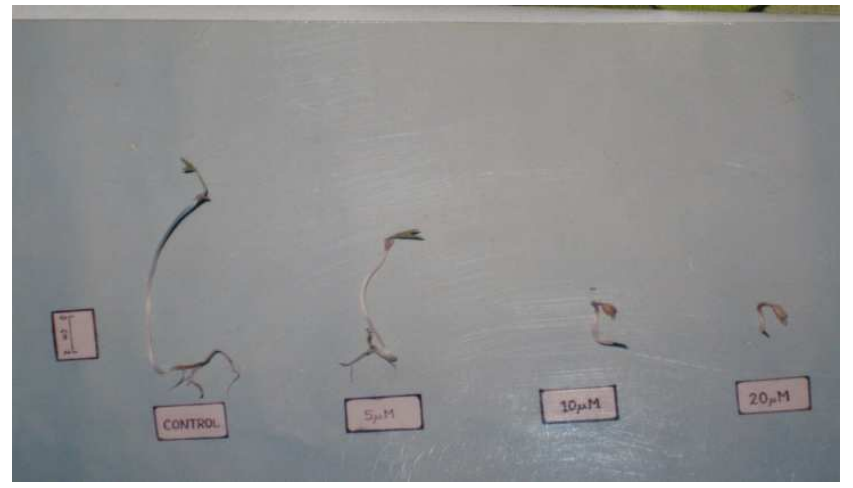

Figure 1. Effect of different concentrations of Sodium arsenate on the growth of 5 day old mungbean seedlings.

Table 1. Effect of A) Sodium arsenate, As(V) and B)Phytohormones (pretreatment for 1 day followed by transfer to As(V) $10 \mu M$ for 4 days more) on shoot and root length, primary leaf area and water content of 5 day old mungbean seedlings.

\begin{tabular}{lllll}
\hline Treatment & Shoot length $(\mathbf{c m})$ & Root length $(\mathbf{c m})$ & Primary leaf area (sq.mm) & Water content (mg water $\mathbf{g}^{-1}$ f.wt.) \\
\hline A)Control & 11.5 & 4.5 & 108 & 295 \\
$5 \mu \mathrm{M}$ As $(\mathrm{V})$ & $6.8(-41)$ & $1.7(-62)$ & $76(-30)$ & $183(-38)$ \\
$10 \mu \mathrm{M}$ As $(\mathrm{V})$ & $2.2(-80)$ & $0.6(-87)$ & $62(-43)$ & $110(-63)$ \\
$20 \mu \mathrm{M}$ As $(\mathrm{V})$ & $1.0(-91)$ & $0.3(-93)$ & $35(-68)$ & $48(-84)$ \\
$\mathrm{B})$ Pretreatment (24h) with: & & & & $166(-44)$ \\
$\mathrm{H}_{2} \mathrm{O}$ & $3.0(-74)$ & $0.8(-82)$ & $72(-33)$ & $263(-11)$ \\
$\mathrm{GA}_{3}$ & $10(-13)$ & $3.8(-15)$ & $97(-10)$ & $245(-17)$ \\
Kinetin & $6.5(-43)$ & $2.0(56)$ & $84(-22)$ & 6.2 \\
S.E. (mean) & 0.3 & 0.1 & 5 & 5.89 \\
C.D. $(5 \%)$ & 0.62 & 0.37 & 5.86 & \\
\hline
\end{tabular}

[Control $=$ Water treatment; $\mathrm{H}_{2} \mathrm{O}=$ Pretreatment with water; Concentration of $\mathrm{GA}_{3}-50 \mu \mathrm{M}$, Kinetin $-10 \mu \mathrm{M}$. Figures in paranthesis are $\%$ decrease (-) over control. Total period of growth -5 days] C.D. - Critical Difference

\subsection{Effect of Arsenate and Growth Promoters on Pigment Content}

Sodium arsenate was found to have significant effect on pigment status and thereby photosynthetic efficiency of mungbean seedlings. There was a linear decrease in the levels of total chlorophyll, carotenoids (carotene and xanthophylls) as well as intensity of chlorophyll fluorescence under increasing concentrations of sodium arsenate (Table 2). 
It is pertinent to suggest that decrease in the amount of the carotenoids in the present work, accelerates the decaying of the chlorophylls. Again, reduction in chlorophyll content may be related to reduced photosynthesis in As toxicated mungbean seedlings. Reduction in net photosynthesis in rice plants caused by As toxicity has been reported earlier [24]. Arsenic may be functional in blocking either the synthesis or the activity of enzyme proteins responsible for chlorophyll biogenesis. A stepwise reduction of Hill activity was also evident due to increasing concentrations of sodium arsenate in comparison to the control (Table 2). In this context, the metalloid, As may be assumed to have caused impaired development and general depression of photosystem II reactions and $\mathrm{O}_{2}$ evolving centers.

Pretreatment with Phytohormones helped to reduce the decrease in chlorophyll content in arsenic toxicated $(10 \mu \mathrm{M})$ seedlings to different degrees. Results obtained from phytohormones pretreated sets signify that the possible damage to non-cyclic electron transport can be relieved partially by the phytohormones $\left(\mathrm{GA}_{3}\right)$ and kinetin (Table 2). $\mathrm{GA}_{3}$ pretreatment was found to stimulate total chlorophyll content [25] and restore Hill reaction partially in $\mathrm{NaCl}$ stressed mungbean plants [26]. From the present work, it is apparent that Phytohormones used here promote the photolysis of water under As induced toxicity with simultaneous increase in the rate of electron flow from excited chlorophyll molecules to the artificial electron acceptor dye DCPIP as evidenced by the rate of reduction of DCPIP.

Table 2. Effect of A) Sodium arsenate, As (V) and B) Phytohormones (pretreatment for 1 day followed by transfer to $10 \mu M$ As(V) for 4 days more) on photosynthetic pigments, chlorophyll fluorescence and Hill activity of 5 day old mungbean seedlings.

\begin{tabular}{|c|c|c|c|c|c|}
\hline Treatment & $\begin{array}{l}\text { Total Chlorophyll } \\
\text { (mg/g fwt.) }\end{array}$ & $\begin{array}{l}\text { Fluorescence } \\
\text { intensity }\end{array}$ & $\begin{array}{l}\text { Carotene content } \\
\left(\mathbf{A}_{425} \mathrm{~g}^{-1} \mathbf{f} \mathbf{w t}\right)\end{array}$ & $\begin{array}{l}\text { Xanthophyll content } \\
\left(\mathbf{A}_{450} \mathrm{~g}^{-1} \text { f wt }\right)\end{array}$ & Hill activity \\
\hline A)Control & 0.82 & 602 & 0.82 & 0.42 & 1.32 \\
\hline $5 \mu \mathrm{M}$ As $(\mathrm{V})$ & $0.62(-24)$ & $451(-25)$ & $0.74(-11)$ & $0.35(-21)$ & $0.82(-38)$ \\
\hline $10 \mu \mathrm{M}$ As (V) & $0.44(-46)$ & $405(-33)$ & $0.64(-22)$ & $0.22(-49)$ & $0.67(-49)$ \\
\hline $20 \mu \mathrm{M}$ As (V) & $0.19(-77)$ & $324(-46)$ & $0.45(-45)$ & $0.14(-65)$ & $0.44(-67)$ \\
\hline \multicolumn{6}{|c|}{ B)Pretreatment (24h) with: } \\
\hline $\mathrm{H}_{2} \mathrm{O}$ & $0.52(-37)$ & $422(-30)$ & $0.65(-21)$ & $0.28(-33)$ & $0.75(-43)$ \\
\hline $\mathrm{GA}_{3}$ & $0.75(-9)$ & $501(-17)$ & $0.77(-6)$ & $0.41(-2)$ & $1.2(-9)$ \\
\hline Kinetin & $0.63(-18)$ & $486(-19)$ & $0.75(-8)$ & $0.36(-14)$ & $1.0(-24)$ \\
\hline C.D. at $5 \%$ & 0.074 & 5.2 & 0.062 & 0.038 & 0.30 \\
\hline S.E. (mean) & 0.02 & 1.4 & 0.02 & 0.01 & 0.02 \\
\hline
\end{tabular}

[Control $=$ Water treatment; $\mathrm{H}_{2} \mathrm{O}=$ Pretreatment with water; Concentration of $\mathrm{GA}_{3}-50 \mu \mathrm{M}$ and Kinetin- $10 \mu \mathrm{M}$. Figures in paranthesis are $\%$ decrease $(-)$ over control. Total period of growth -5 days] C.D. - Critical Difference

\subsection{Effect of Arsenate and Growth Promoters on Sucrose Metabolism}

The main photosynthate of plants-sucrose metabolism of germinating mungbean seeds was immensely affected by As. Reducing sugar content of mungbean seedlings showed a declining trend with increasing concentrations of sodium arsenate (Table 3). Reduction in reducing sugar content can be easily correlated with growth inhibition. This could be an effect of reduced leaf area, chlorophyll content and ultimately lesser photosynthetic rate due to As toxicity. It is also to be noted that lower level of reducing sugar in the treated plants finds correlation with lower metabolic status in these plants. Decline in reducing sugar content might also be due to reduced $\alpha$-amylase activity, which resulted in reduced hydrolysis of reserve polysaccharides [27]. However, concomitant with the increase in concentration of arsenate, starch content of the seedlings were found to be increasing. It may be assumed that mungbean seedlings under arsenate toxicity accumulated more of starch as reserved polysaccharide and for osmotic adjustment. Elevated levels of starch content have also been reported in arsenate treated rice seedlings [20]. The perturbation of carbohydrate level under arsenate stress condition might have impaired the growth and metabolism of mungbean seedlings which is also relevant from the morphological data.

Enhancement in reducing sugar and non-reducing sugar content of arsenate treated seedlings was observed if they have been soaked in $\mathrm{GA}_{3}$ and Kinetin prior to transfer to toxic concentrations of sodium arsenate $(10 \mu \mathrm{M})$ while the seeds which received only water as pretreatment, failed to show much increment in reducing sugar content $(43 \%$ decrease from control) as shown in Table 3. Starch content of the seedlings was also found at comparatively decreased level closer to control in Phytohormones pretreated sets. Increased reducing sugar content due to pretreatment with $\mathrm{GA}_{3}$ might be due to accelerated $\alpha$ amylase activity which promoted hydrolysis of reserve polysaccharides ultimately resulting in increased sugar content [28]. $\mathrm{GA}_{3}$ has also been reported to reverse the $\mathrm{NaCl}$-induced inhibition of amylase-isozyme synthesis [29]. Growth promoters induce increase in sugar content thus helping osmotic potential adjustment in the cell. It can be concluded that effect of As-induced toxicity could be appreciably overcome by using few Phyohormones such as $\mathrm{GA}_{3}$ and Kinetin, which may serve to maintain normal metabolic pathway toward the synthesis and utilization of carbohydrates. 
Table 3. Effect of A) Sodium arsenate, As(V) and B)Phytohormones (pretreatment for 1 day followed by transfer tol0 $\mu M$ As $(V)$ for 4 days more) on Reducing sugar content, non-reducing sugar content and Starch content of 5 day old mungbean seedlings.

\begin{tabular}{|c|c|c|c|c|c|c|}
\hline Treatment & $\begin{array}{l}\text { Reducing sugar } \\
\text { content (mg/g f wt) }\end{array}$ & Reduction (\%) & $\begin{array}{l}\text { Non-Reducing sugar } \\
\text { content (mg/g f wt) }\end{array}$ & Reduction (\%) & $\begin{array}{l}\text { Starch content } \\
\text { (mg/g f wt) }\end{array}$ & Promotion (\%) \\
\hline A)Control & 3.92 & - & 5.22 & - & 81 & - \\
\hline $5 \mu \mathrm{M}$ As $(\mathrm{V})$ & 2.84 & 28 & 3.52 & 33 & 90 & 11 \\
\hline $10 \mu \mathrm{M}$ As $(\mathrm{V})$ & 1.94 & 50 & 3.14 & 40 & 94 & 16 \\
\hline $20 \mu \mathrm{M}$ As (V) & 1.56 & 60 & 2.52 & 52 & 99 & 22 \\
\hline \multicolumn{7}{|l|}{$\begin{array}{l}\text { B)Pretreatment } \\
\text { (24h)with: }\end{array}$} \\
\hline $\mathrm{H}_{2} \mathrm{O}$ & 2.22 & 43 & 3.64 & 30 & 90 & 11 \\
\hline $\mathrm{GA}_{3}$ & 3.42 & 13 & 4.28 & 18 & 84 & 4 \\
\hline Kinetin & 3.24 & 17 & 4.15 & 20 & 82 & 1 \\
\hline C.D at $5 \%$ & 0.41 & - & 0.45 & - & 7.86 & - \\
\hline S.E. (mean) & 0.04 & - & 0.04 & - & 3.5 & - \\
\hline
\end{tabular}

[Control = Water treatment; $\mathrm{H}_{2} \mathrm{O}=$ Pretreatment with water; Concentration of $\mathrm{GA}_{3}-50 \mu \mathrm{M}$ and Kinetin-10 $\mu \mathrm{M}$. Total period of growth -5 days] C.D.-Critical Difference

\section{Conclusion}

From the results of the present investigation, it can be concluded that Sodium arsenate is extremely toxic for plant growth. Arsenate affects the early growth of mungbean seedlings, particularly the root growth. Arsenate also damaged the photosynthetic machinery by causing reduced chlorophyll and carotenoid contents and also led to perturbations in sucrose metabolism. Pretreatment with Phytohormones, $\mathrm{GA}_{3}$ and Kinetin ameliorated the injurious effects of arsenate stress to some extent by increasing growth and photosynthetic pigments. Sucrose metabolism was also recovered to some extent.GA $\mathrm{G}_{3}$ and Kinetin have emerged out to be effective ameliorative chemicals which possibly brought down the toxic effects of sodium arsenate in the Mungbean seedlings and thus their promoting effects on seedling growth parameters were well visible. Pretreatment of mungbean seeds with $\mathrm{GA}_{3}$ and Kinetin might allow the seeds to germinate and initiate growth in arsenic contaminated water which in natural conditions leads to death of seedlings.

\section{Acknowledgement}

I offer my deep sense of gratitude and respect to Dr. Subhendu Mukherji, Professor of Botany, University of Calcutta, under whose supervision and guidance, this research work was carried out. I am also indebted to Laboratory of Plant Physiology, Department of Botany, University of Calcutta, for supplying all the necessary chemicals and instruments.

\section{References}

[1] Rahman, M. M., Rahman, M. A.,Maki, T. and Hasegawa, H. (2012). "Phytotoxicity of arsenate and salinity on early seedling growth of rice (Oryza sativa L.): A threat to sustainable rice cultivation in South and S E Asia”. Bull. Environ. Contam.Toxicol., 88:695-702.
[2] Swarnakar, A. (2016) "Mitigation of Toxic effects of Sodium Arsenate on germination, seedling growth and amylolytic enzyme of Mungbean seedlings with Macronutrients, Micronutrients and Organic acids. Int.J.Curr.Microbiol.App.Sci., 5 (12): 151-160.

[3] Abedin, M. J. and Meharg, A. A. (2002) "Relative toxicity of arsenite and arsenate on Germination and early seedling growth of rice (Oryza sativa L.)".Plant and soil,243 (1): 57-66.

[4] Maitra,P. and Mukherji, S. (1979) "Effect of Lead on nucleic acid and protein contents of rice (Oryza sativa L.) seedlings and its interaction with IAA and $\mathrm{GA}_{3}$ in different plant systems". Indian J. Exp. Biol.,17: 929-931.

[5] Chakrabarti, N. and Mukherji, S. (2003) "Alleviation of $\mathrm{NaCl}$ stress by pretreatment with phytohormones in Vigna radiata L.”Biol. Plant.,46: 589-594.

[6] Singh, H. and Dara, B.L. (1971) "Influence of presoaking of seeds with gibberellins and auxins on growth and yield attributes of wheat (Triticum aestivum L.) under high salinity, sodium adsorption ratio and boron levels". Indian J. Agr. Sci.,41: 998-1003.

[7] Sawan, Z.M, Mohamed A.A, Sakr R.A, Tarrad. A.M (2000) "Effect of kinetin concentration and methods of application on seed germination, yield components, yield and fibre properties of the Egyptian cotton (Gossypium barbadense)". Environmental and Experimental Botany,44 (1): 59-68.

[8] Mehta P. M., M. T. Jacob and B. V. N. Rao. (1974) "The effects of ascorbic acid, kinetin, coumarin and their combination on the germination, growth and enzyme catalase of Cajanus cajan var. selection 4-1A". Geobios 1: 53-59.

[9] Ogunwole A. A. and Otusanya,O. O. (2015) "Interaction of Aqueous Extracts of Tithoni adiversifolia, Chromolaena odorata and Kinetin Induced Growth and Accumulation of Chlorophyll in Hibiscus sabdariffa". Inter. J. Agri. Innovations and Res., 3 (6):1610-1619.

[10] Bhatnagar V. K. and G. R. Rastogi. (1980) "Effect of some growth regulators on Zea mays".Geobios7: 183-184.

[11] Abdollah Bahrani (2015). "Kinetin and Abscisic acid effects on seed germination and seedlings growth of Maize (Zea mays L.) under salt stress condition". ARPN Journal of Agricultural and Biological Science.10 (9):351-357. 
[12] Nandwal, A. S. and Bharati, S. (1982) "Effect of kinetin and IAA on growth, yield and nitrogen fixing efficiency of nodule in pea (Pisum sativum)". Indian J. Plant Physiol. 25:358-363.

[13] Merchan, F., de Lorenzo L., Rizzo, S. G., Niebel, A., Manyani, H., Frugier, F., Sousa C. and Crespi, M. (2007) "Identification of regulatory pathways involved in the reacquisition of root growth after salt stress in Medicago truncatula". Plant J. 51: 1-17.

[14] Arnon, D. I. (1949).“Copper enzyme in isolated chloroplasts. Polyphenol Oxidase in Beta vulgaris. ”Plant Physiol.,24: 1-15.

[15] Davies, B. H. (1965). "Analysis of Carotene pigments",in Chemistry and Biochemistry of Plant Pigments. Goodwin, T. W. Ed. Academic press.New York: 489-531.

[16] Vishniac, W. (1957) "Methods for the study of Hill reaction", in Methods of Enzymology"Colowick, S.P. and Kaplan, N. O. Eds. Academic press.New York, 4: 342-355.

[17] Miller G. L. (1972) "Use of dinitrosalicylic acid reagent for determination of reducing Sugars". Anal. Chem., 31: 426-428.

[18] McCready, R. M., Guggolz, J., Silviera, V. and Owens, H.S. (1950). "Determination of Starch and amylase in vegetables". Anal. Chem., 22: 1156-1158.

[19] Zidan, I., Azaizen, I. I. and Neuman, P. M. (1990) "Does salinity reduce growth in maize roots epidermal cells by inhibiting their capacity for cell wall acidification?" Plant Physiol., 93:7-11.

[20] Choudhury, B, Mitra, S. and Biswas, A. K. (2010). "Regulation of sugar metabolism in rice (Oryza sativa L.) seedlings under arsenate toxicity and its improvement by phosphate". Physiol. and Mol. Biol.of Plants.16 (1): 59-68.

[21] Carbonell - Barrachina,A. A.,Burlo - Carbonell, F.,MataixBeneyto, J. (1995).“Arsenic uptake, distribution and accumulation in tomato plants: effect of arsenite on plant growth and yield”. J. Plant Nutr., 18 (6):1237-1250.

[22] Stoeva, N., Berova, M. and Zlatev, Z. (2005) "Effect of arsenic on some physiological parameters in bean plants". Biologia Plantarum., 49 (2): 293-296.

[23] Swarnakar, A. and Mukherji, S. (2005). "Amelioration of arsenic toxicity by phosphate salts in mungbean seedlings". J. Environ. Biol.,26 (3):551-555.

[24] Azizur, R. M., Hasegawa, H., Rahman, M. M., Islam, M. N., Miah, M.A.M. and Tasmen, A. (2007) "Effect of arsenic on photosynthesis, growth and yield of five widely cultivated rice (Oryza sativa L.) varieties in Bangladesh". Chemosphere, 67: 1072-1079.

[25] Vidhu and Murty, Y. S. (1985) "Growth substance mediated chlorophyll changes in Tagetes erecta L". Plant Physiol and Biochem., 12 (2): 93-96.

[26] Chakraborti, N. and Mukherji, S. (1994) "Effect of gibberellic acid and kinetin pretreatment as foliar spray on chlorophyll content, chlorophyllase enzyme activity, photosynthetic noncyclic electron transport and $\mathrm{CO}_{2}$ uptake in $\mathrm{C}_{3}$ glycophyte mungbean under salt stress". Plant Physiol. Biochem.,21: 59-64.

[27] Zaidi, P. H. and Singh, B. B. (1995). "Effect of growth regulators on IAA- oxidase and Peroxidase activity in soybean under salinity”. Indian J.Plant Physiol.,38 (4):337-339.

[28] Sarin, M. N. and Narayanan, A. (1968) "Effect of soil salinity and growth regulators on germination and seedling metabolism of wheat". Physiol.Plant.,21: 1201-1209.

[29] Acharya, U. T., Prakash, L. and Prathapasenan, G. (1990) "Effect of gibberellic acid on seedling growth and carbohydrate metabolism during germination of rice (Oryza sativa L.,var. GR-3) under saline condition”. J. Agron. Crop. Sci., 165 (1): 6-13. 